\title{
Transoral Laser Excision of a Pyriform Sinus Cyst
}

\author{
Sang Joon Lee ${ }^{1}$ \\ Phil-Sang Chung ${ }^{1}$ \\ Sang Yong Chung ${ }^{2}$ \\ Seung Hoon Woo ${ }^{1}$
}

${ }^{1}$ Department of Otolaryngology-Head and Neck Surgery, Dankook University College of Medicine, Cheonan, Korea

${ }^{2}$ Su ENT Clinics, Incheon, Korea

\section{Correspondence}

Seung Hoon Woo

Department of Otorhinolaryngology Head and Neck Surgery, Dankook University School of Medicine, 201 Manghyang-ro, Dongnam-gu, Cheonan 31116, Korea

Tel.: +82-41-550-1781

Fax: +82-41-550-7837

E-mail: lesabyahanmail.net

(C) Korean Society for Laser Medicine and Surgery

(c) This is an open access article distributed under the terms of the Creative Commons Attribution NonCommercial License (http://creativecommons.org/ licenses/by-nc/4.0) which permits unrestricted noncommercial use, distribution, and reproduction in any medium, provided the original work is properly cited.

\begin{abstract}
Pyriform sinus cyst is a rare disease. This disease can be found by chance or appear as lymph nodes with cancer, infections, shortness of breath, or airway compromise, and can be an unusual cause of dysphonia. This paper presents a case of a pyriform sinus cyst in the pharyngeal wall of the left pyriform sinus, which presented as neck discomfort in a 63-year-old female. The plan was to remove this cyst with a transoral $\mathrm{CO}_{2}$ laser because a $\mathrm{CO}_{2}$ laser is a useful tool for removing cysts without bleeding and consuming time. The excision was performed successfully. Transoral laser pyriform sinus cyst excision is a simple, safe, and effective method for the treatment of pyriform sinus cysts. This procedure is likely to be used as a selective treatment when managing this condition.
\end{abstract}

\section{Key words}

Pyriform sinus; Laser; Cyst; Excision 


\section{INTRODUCTION}

Pyriform sinus cysts are usually benign. They constitute approximately $5 \%$ of benign hypopharynx lesions. ${ }^{1,2}$ DeSanto et al. ${ }^{3,4}$ reported that $51 \%$ of laryngopharyngeal cysts originate from the epiglottis, with most occurring at the lingual surface. Blocking mucosal ducts while maintaining mucus is thought to be the cause of cysts. Symptoms may vary depending on the age of the patient and the size and location of the cyst. A foreign body sensation in the throat is the most common symptom. Airway compromise may occur in infants with a large cyst. ${ }^{5}$ Excision is the conventional treatment for pyriform sinus cyst. ${ }^{5}$ However, rupture of cysts often occurs during surgical manipulations. This can make it difficult to completely remove the cyst, especially when the cyst is deeply stretched in the tissue. This report shows the safety and effectiveness of laser excision of pyriform sinus cyst via a transoral route.

\section{CASE REPORT}

An age 63 female patient with pyriform sinus cyst excision using micro laryngeal surgery with $\mathrm{CO}_{2}$ laser was performed. Preoperative and postoperative laryngoscopy examinations were performed.

The operation was performed under general anesthesia. A direct laryngoscope was inserted with adequate depth to expose the pyriform sinus and cyst. The diameter of the cyst was $0.5 \mathrm{~cm}$. A surgical microscope equipped with a $400 \mathrm{~mm}$ objective lens and a laser was attached positioned so that the laser beam could pass directly through the opening of the laryngoscope.

A microspot (spot of $250 \mathrm{~m}$ ) with a power of $2 \mathrm{~W}$ (continuous mode, slightly defocused) was used to mark and remove the cutting line surrounding the cyst (Fig. 1). There was no perioperative bleeding or airway swelling. The entire surgery was completed within 20 minutes. The pathology was routinely checked for these lesions.

\section{DISCUSSION}

The pyriform sinus cyst is a rare lesion. DeSanto et al. ${ }^{3,4}$ reviewed 238 cases of laryngeal/pharyngeal cysts at the Mayo Clinic over 10 years and found that 134 (52\%) cases originated from the epiglottis and pyriform sinus lesion comprised only few cases. When a pyriform sinus cyst increases in size, it may gradually distort the larynx and fill the pyriform sinus. Pyriform sinus cysts can occur at any age, but a greater prevalence is observed age 50-60.

Symptoms depend on the size of the cyst, age of the patient, and airway extension. Neonates and infants may present with dyspnea, stridor, failure to thrive, or difficulty in feeding, because they have small airways. However, most adults with pyriform sinus cysts are asymptomatic or have mild symptoms such as a throat lump, voice alteration, or dysphagia. ${ }^{1-5}$

The exact origin and cause of pyriform sinus cysts remain unknown, but they are thought to originate from the obstructed ducts of the submucosal glands and sub-
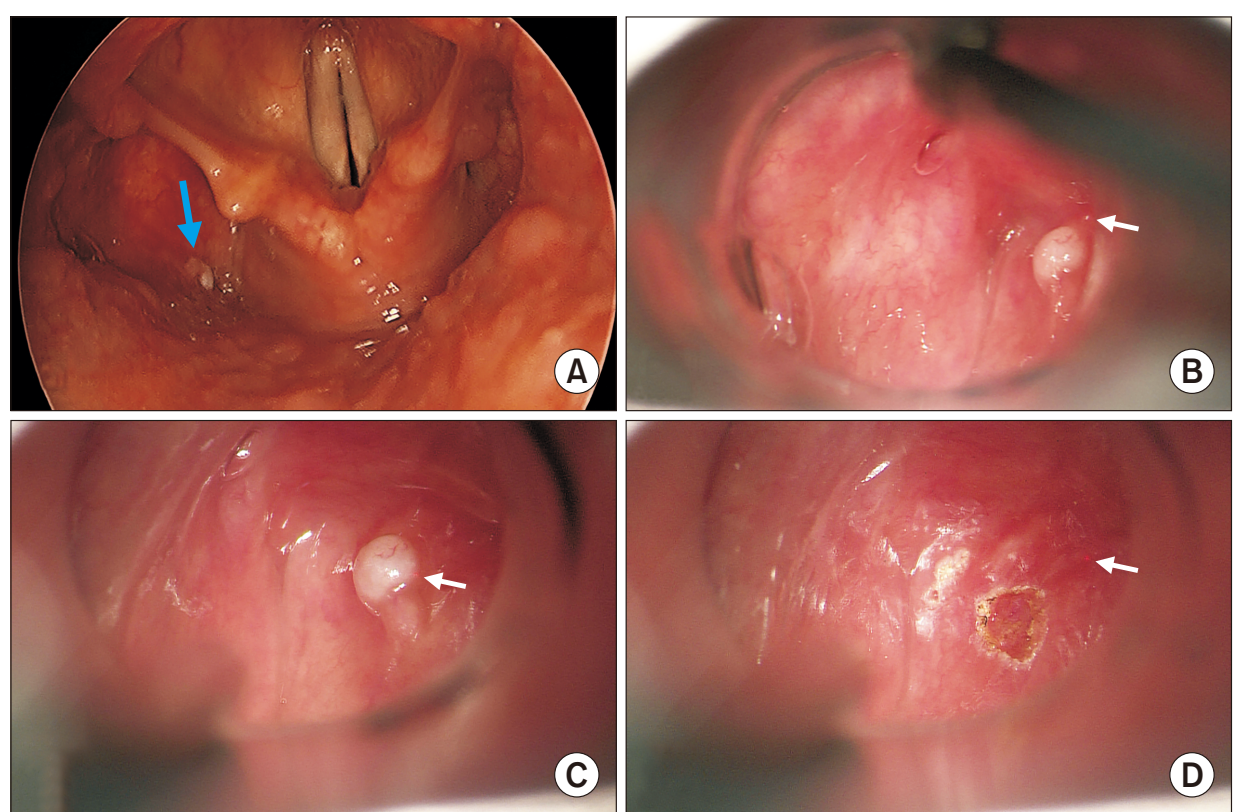

Fig. 1. (A) A Pyriform sinus cyst (blue arrow) originating from the post pharyngeal wall. (B) $\mathrm{A} \mathrm{CO}_{2}$ laser (white arrow) was used to mark the cutting line encircling the cyst. (B, C) Thick mucoid content flowed freely from the cyst cavity once the laser incision was made through the cyst capsule. (D) The Pyriform sinus cyst was removed. 
sequent dilatation of the glands. ${ }^{3,4}$ The epithelial lining of the cyst is most often stratified squamous epithelium, but cuboidal, columnar, and ciliated columnar epithelia have also been reported. Because pyriform sinus cysts have been confused with cancer, surgical removal and need to pathologic confirmation. However, complete surgical removal with cold instruments is not only easy to bleed from the wound, but can also be time consuming and difficult because the cyst ruptures easily during operation. In contrast, use of a laryngeal microscope with a $\mathrm{CO}_{2}$ laser provides excellent depth perception and good magnification, allowing a more accurate assessment of the resection level. Its advantages of superior surgical precision and control, and intrinsic hemostatic properties, explain the lower incidence of postoperative edema and pain and the ease of use compared with conventional methods when performing excision of a pyriform sinus cyst. Postoperative follow-up with a laryngoscope showed no obvious scar or cyst recurrence at the patient's lesion site. The advantages of this technique include minimal invasiveness, time saving, rapid recovery, and a very low recurrence rate.

The laryngeal microscopic approach to laser excision of a pyriform sinus cyst is simple and effective. This technique may serve as a treatment of choice in management of this condition.

\section{ACKNOWLEDGMENTS}

This research was supported by the Leading Foreign
Research Institute Recruitment Program through the National Research Foundation of Korea (NRF), funded by the Ministry of Science and ICT (MIST) Igrant NRF2018K1A4A3A02060572); and by the Korea Health Technology R\&D Project through the Korea Health Industry Development Institute (KHIDI), funded by the Ministry of Health and Welfare, Republic of Korea (grant HI15C1524) The authors have no other funding, financial relationships, or conflicts of interest to disclose.

\section{CONFLICT OF INTEREST}

The authors declare no conflicts of interest.

\section{REFERENCES}

1. Holinger $\mathrm{PH}$, Johnston $\mathrm{KC}$. Benign tumors of the larynx. Ann Otol Rhinol Laryngol 1951;60:496-509.

2. Newman BH, Taxy JB, Laker HI. Laryngeal cysts in adults: a clinicopathologic study of 20 cases. Am J Clin Pathol 1984;81:715-20.

3. DeSanto LW, Devine KD, Weiland LH. Cysts of the larynx-classification. Laryngoscope 1970;80:145-76.

4. DeSanto LW, Devine KD, Weiland LH. Cysts of the larynx-classification. Laryngoscope 2015;125:2629.

5. Dahm MC, Panning B, Lenarz T. Acute apnea caused by an epiglottic cyst. Int J Pediatr Otorhinolaryngol 1998;42:271-6. 